\title{
Social comparison increases the dispersion and predictability of effort
}

\section{and performance}

\author{
Milena Tsvetkova ${ }^{\mathrm{a}}$, Sebastian Müller ${ }^{\mathrm{a}}$, Oana Vuculescu ${ }^{\mathrm{b}}$, \\ Haylee Ham ${ }^{\mathrm{c}, \mathrm{d}}$, and Rinat Sergeev ${ }^{\mathrm{c}, \mathrm{e}}$ \\ a Department of Methodology, London School of Economics and Political Science, London WC2A 2AE, \\ United Kingdom \\ b Department of Management, Aarhus University, 8210 Aarhus, Denmark \\ ${ }^{c}$ Laboratory for Innovation Science at Harvard, Harvard Business School, Boston, MA 02134 \\ ${ }^{\mathrm{d}}$ Institute for Quantitative Social Sciences, Harvard University, Cambridge, MA 02138 \\ e Harvard Business School, Boston, MA 02163
}

\begin{abstract}
Ranking in contests and competitions is often used to motivate individual contributions but it can have negative impact on the group. Here, we study the effect of social comparison on the dispersion and predictability of individual performance. We hypothesize that the effects of social comparison on effort will differ for top-performers and bottom-performers in a way that the inequality between the two increases. We use a quasi-experimental design to test our predictions with data from Topcoder, an online crowdsourcing platform that publishes computer programming contests. We find that in contests where the submitted code is evaluated against others' submissions, rather than using an absolute scale, top-performers increase their effort while bottom-performers decrease it. As a result, relative scoring leads to a higher dispersion and somewhat higher predictability of performance, strengthening the status quo and precluding underperformers from engaging and learning. Our findings expose the drawbacks of using gamified competitions, rankings, and relative evaluations in learning environments and organizations.
\end{abstract}




\section{Introduction}

Social comparison is deeply rooted in our nature. According to the eminent social psychologist Leon Festinger, we have a powerful drive to gain accurate self-evaluations and we often achieve this by comparing our opinions and skills to those of others [1]. Even more importantly, we tend to seek a better standing in relation to others, that is, we pursue distinction and status [2]. We have evolved and adapted for status seeking because reproductive success and survival depend on comparative advantage rather than absolute levels of fitness [3]. Indeed, gaining more than others, regardless of the absolute value of the gain, affects us neuro-physiologically by activating the reward regions in our brains [4].

Whether intentional or not, social comparison induces competitive behavior [1, 5]. This occurs in contests and tournaments, where rewards depend on rank performance [6, 7], but also in situations where social comparison is not linked to financial incentives [8, 9, 10]. Competition increases individual effort: for example, individual contests drive effort expenditure beyond what is rational [6, 11, 12], which makes them useful in efforts to spur innovation [13, 14, 15]. However, competition may negatively affect group outcomes. Within-group competition for scarce resources reduces trust and trustworthiness [16], decreases contributions to public goods [17], diminishes cooperation [18, and hinders agreement in bargaining situations [19]. It also increases spiteful behavior and sabotage [20, 21, 22].

In this study, we investigate the effects of social comparison on a different group-level outcomeinequality in effort and performance. We focus on learning and creative tasks, in which input, or effort, is positively correlated with but still distinct from output, or performance. Effort is related to the level of engagement and mental investment, while performance indicates the level of learning, innovation, and creativity that has occurred. Some social settings benefit from a single best performing contributor or a higher average performance: for example, multiple record breaking performances can fuel audience interest in a sports tournament, while a single brilliant idea can generate value in an innovation contest. Other social contexts, however, benefit more from an even distribution of effort and performance. Education settings, online user-contribution communities, and more generally, organizations, require most of their members to be engaged in order to maintain their size and serve their mission. Regarding schooling, for example, sociologists recognize the provision of equality of opportunity and the reduction of achievement gaps as an important problem for contemporary Western societies [23]. In the context of organizations, scholars and managers acknowledge that inequality, including experiental inequality, can decrease individual productivity and job satisfaction and lower organizational performance [24, 25].

We focus on two aspects of inequality of effort and performance under social comparison - dispersion and 
predictability. On the one hand, lower inequality implies more consistent levels of effort and engagement across individuals, resulting in more evenly distributed outcomes, with a smaller difference between worst and best performers. On the other hand, lower inequality also entails an equal opportunity for everyone to perform well, making outcomes less correlated with prior skills and achievements. In other words, lower inequality involves lower dispersion of effort and performance and lower predictability of performance. In contrast, higher inequality entails more dispersed and predictable performance.

Previous literature has not directly studied the effects of social comparison on inequality in effort and performance but it nevertheless contains some insights and suggestive empirical evidence, albeit contradictory. On the one hand, in his seminal essay, Festinger suggests that social comparison drives competition in a direction that facilitates convergence towards uniformity [1]. He argues that social comparison increases underachieving individuals' motivation to perform better and hence, their effort increases. In addition, overachievers become willing to help underachievers while, at the same time, underachievers cooperate less with overachievers. Further, he mentions that when the achievement gap is too large, individuals will avoid comparison by simply avoiding or leaving the group. All of these mechanisms - increasing effort, cooperating with underachievers, undermining overachievers, or self-selecting out of an unfavorable comparison group - serve to equalize outcomes and thus decrease inequality in performance. Two of these mechanisms are empirically supported: the tendency to select into and out of contests [26] and the tendency to sabotage winners in contests [27].

However, empirical research on contests and tournaments contradicts Festinger's expectation that underachievers increase effort. Compared to piece-rate schemes, contests, all-pay auctions, and tournaments result in higher variance in individual effort [6, 12]. Similarly, the contributions to a public good increase in dispersion when individuals are incentivized with tournament rewards for contributing [11]. These outcomes can be explained with demographic differences and heterogeneous preferences towards winning, risk, losses, and inequality [6]. In essence, social comparison may have differing effects on different people: some may become more competitive, while others may lose interest and decrease effort as their chances of winning drop. This implies that social comparison could result in a rich-get-richer and poor-get-poorer dynamics that widen existing ability differences and make performance more predictable, going directly against Festinger's arguments. We hypothesize that social comparison tends to do exactly this.

When individual achievement is measured and evaluated in reference to others, success becomes a moving target. Individuals who put the effort and improve their personal performance may lack a sense of accomplishment because others may still be advancing faster. This may trigger feelings of unfairness, 
resentment, even relative deprivation among those on the bottom of the chart. These subjective experiences have been linked to short-sightedness, emphasis on small and immediate rewards compared to large and delayed ones [28], and more risky behavior [2]. Conversely, those on the top of the chart may experience the opposite effect, whereby a serendipitous move could increase their confidence and motivation to persevere. Indeed, prior empirical research shows that higher-ranked individuals behave more competitively than lower-ranked individuals [29]. In short, social comparison exaggerates small differences in ability and effort but individuals' reaction to the ongoing results could feedback into individuals' behavior in a way that reinforces these differences.

We thus expect that social comparison will result in higher individual effort among high-ranking individuals and lower individual effort among low-ranking individuals. This in turn will produce higher inequality by increasing both the dispersion and the predictability of individual performance. To test these predictions, we apply advanced causal inference techniques on observational data from online computer programming contests. In the specific context we study, individuals iteratively work on a solution to a creative task in order to gain experience and reputation, where, in some cases, their work is evaluated against an absolute standard and in other, against everyone else's solutions. This situation resembles how students learn in a school setting, academic researchers compete for high-impact publications and grants, and knowledge employees train and seek promotion. Our setting offers an unprescedentedly detailed and large data that allow us to measure ability, effort, and performance in a meaningful way, which may not be feasible in these other settings. Additionally, the methods we employ allow us to make causal claims in a realistic context, circumventing some of the disadvantages of in-lab controlled randomized experiments related to internal and external validity.

\section{Results}

We analyze data from the online crowdsourcing platform Topcoder. Topcoder maintains a community of programmers who regularly compete in programming challenges to win monetary prizes or improve their rating and reputation [15, 30, 31, 32. Each Topcoder challenge poses a well-defined problem and has a unique leader board and prize structure. Some challenges offer monetary awards while others only offer contestants the opportunity to gain experience and improve their rating. To study the effects of social comparison, we differentiate between challenges in which the score shows performance relatively to the

performance of other solutions (relative scoring) and challenges in which the score is a measure of the performance of the solution in a test (absolute scoring). 
Our data comprise 189,659 successful code submissions by 17,000 individuals in 367 challenges in the period from 15 December, 2005 until 1 April, 2018. The data cover almost all "marathon matches" in the Data Science track that were posted since the platform was launched, except for a handful of challenges with proprietary data. Marathon matches are longer running challenges that allow coders to make repeated submissions and receive provisional scores for their current performance, giving them the opportunity to improve their solutions.

First, we identify sub-groups, or strata, of challenges that are similar in size, duration, difficulty, reward structure, and task, and only differ in the scoring procedure they apply. We note that none of the matched challenges have monetary or nonmonetary prizes (Table S2). This means that they are challenges designed and posted by Topcoder with the purpose to keep their user community stimulated and engaged. Coders contribute to such challenges in order to learn and practice and in order to establish their reputation in the community [31, 32].

Using simple comparison of means analysis (Fig. 1), we find that, compared to challenges with absolute scoring, challenges with relative scoring have slightly higher dispersion of individual performance, higher predictability of performance, and higher dispersion of effort. We test these differences with regression models that weigh the challenges by stratum and control for the challenge characteristics used in the matching (Model 1 and 3 in Table S4). The differences for performance and effort dispersion are not statistically significant but the higher predictability of performance in the relatively scored challenges is (Model 2 in Table S4). In other words, we find statistical evidence that performance is more highly correlated with prior skills in groups that provide feedback based on social comparison.

Unfortunately, the group-level analyses do not allow us to determine the extent to which these results are driven by self-selection in or out of the treatment and the extent to which they are driven by the actual modification of behavior. For example, we match by and control for average contestant experience, but it appears that relatively scored challenges attract individuals with slightly higher Topcoder ratings, which could explain part of the observed higher predictability in performance. More importantly, however, the absence of differences in the dispersion of effort and performance at the group level could be driven by a treatment effect that differs by individual characteristics. In fact, we explicitly hypothesized that low-performers will respond to social comparison differently from high performers.

To investigate the behavioral effects of social comparison, we conduct causal analysis at the individual level. We abstract from the self-selection bias by using a cross-over experimental design. In cross-over experiments, subjects are exposed to both the treatment and control and their outcomes are measured at 

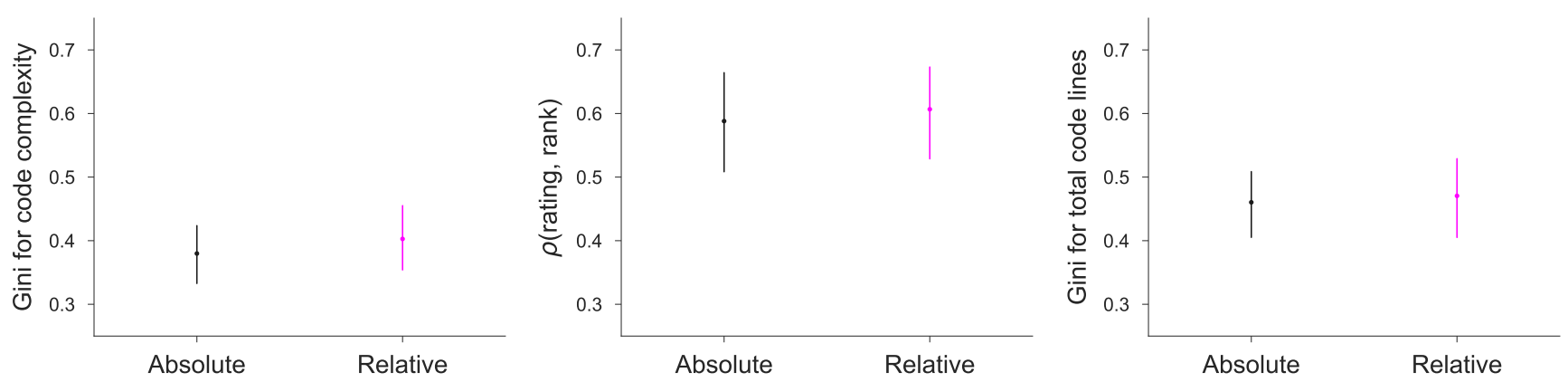

Figure 1: Challenges with relative scoring appear to have slightly higher dispersion of individual performance (left), predictability of performance (middle), and dispersion of effort (right). Statistical models that control for additional challenge characteristics, however, show that only the effects on predictability are significant (Table S4). Error bars indicate 95\% confidence intervals around the means, which are estimated over the matched challenge strata. Performance dispersion is measured with the Gini coefficient of the cyclomatic complexity of the code in the final submission, predictability with the Spearman rank correlation between the coder's challenge-specific percentile rank by rating and their percentile rank by final score, and effort with the Gini coefficient of the total number of code lines written for the challenge.

each occasion. In our case, we investigate the effort and outcomes of all individuals who participated in at least one relatively scored and at least one absolutely scored challenge in any of the strata of otherwise similar challenges we identified for the group-level analysis. Within this design, we analyze how relative scoring affects individuals of different abilities, where we measure ability with the user's current Topcoder rating in relation to the other challenge contestants' ratings (Fig. 2).

We find that the difference in performance, as measured by the computational complexity of the final submitted code, is more extreme between low-rated and high-rated individuals in challenges with relative scoring compared to challenges with absolute scoring. This difference is significant when we test it in regression models that account for variability by stratum, challenge, and individual, control for ordering effects, and weigh the observations by stratum $\left(\Delta \chi^{2}(3 d f)=11.532, p=0.009\right.$, Models 1.1 and 1.2 in Table S5). The effect is mainly driven by the higher code complexity produced by coders rated above the 50th percentile. The left panel in Figure 2 reveals that relatively scored challenges tend to result in more sophisticated code solutions, mainly because higher-rated individuals perform better; the lowest-rated individuals, in contrast, do not appear to learn and benefit more from relatively scored challenges.

Looking at the relative positions in the challenge, the U-shaped relationship in the middle panel in Figure 2 suggests a tendency for higher predictability of performance at the lower and higher ends of rating. It appears that relatively scored challenges make the performance of low-rated individuals more predictable, while that of individuals in the $60-80$ percentile by rating less predictable. This would suggest that relatively scored challenges are more likely to reinforce the position of low-rated coders but also more 

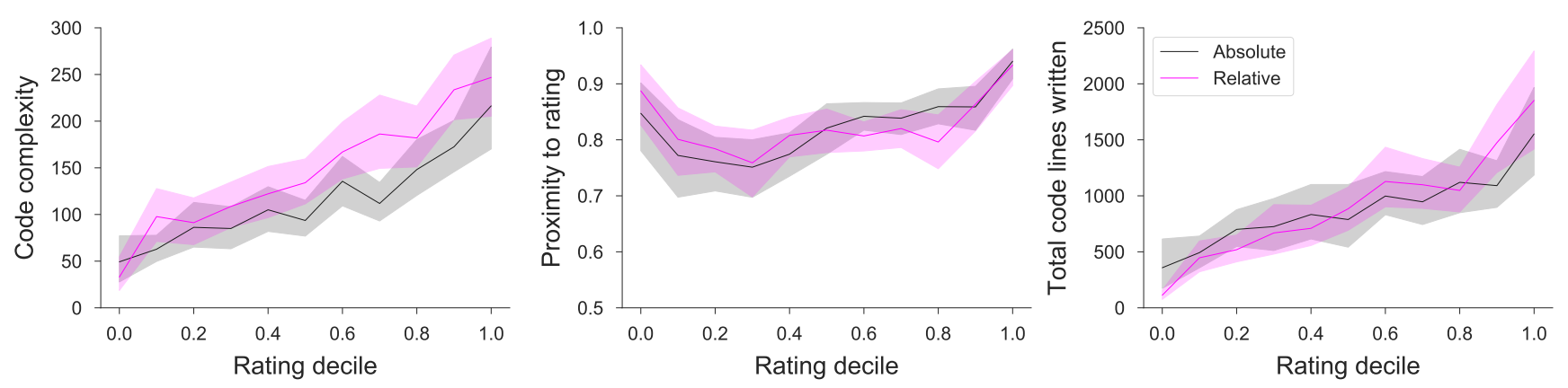

Figure 2: Low-rated individuals put less effort (right) and perform worse (left) compared to high-rated individuals in challenges with relative scoring than in challenges with absolute scoring; there is also indicative evidence that their performance is more predictable (middle), although this result is not statistically significant (Table S5). The shaded area indicates $95 \%$ confidence intervals around the means, which are estimated over 954 stratum-individuals. Performance is measured with the cyclomatic complexity of the code in the last submission, predictability with one minus the absolute difference between the coder's challenge-specific percentile rank by rating and their percentile rank by final score, and effort with the number of new code lines the coder wrote over the entire duration of the challenge.

likely to produce upsets or surprise wins for above-average performers. This difference, however, does not reach statistical significance in our data and models: comparing the model without treatment effects (Model 2.1 in Table S5) and the model with treatment effects for the intercept and slope of the relationship between rating and predictability in the treated group (Model 2.2 in Table S5) yields $\Delta \chi^{2}(2 d f)=3.974$ and $p=0.137$. Thus, the results suggest that the higher predictability of performance we observe in relatively-scored challenges cannot be explained with behavioral effects only but are additionally driven by selection effects. Indeed, we find that relatively scored challenges tend to have individuals with ratings that are sightly higher on average, as well as more widely dispersed (Fig. S3).

The difference between low-rated and high-rated individuals is most pronounced when it comes to effort. Compared to absolutely scored challenges, in relatively scored challenges low-rated individuals work less on their code, while high-rated individuals work more (Fig. 2). The statistical models reveal that this difference is significant $\left(\Delta \chi^{2}(2 d f)=7.633, p=0.022\right.$; Model 3.1 and 3.2 in Table S5). The negative effects of relative scoring on the effort exerted by low-rated individuals are also evident when we study how many submissions they made and how long they stayed active in the challenge (Fig. 3). The difference for number of submissions is statistically significant $\left(\Delta \chi^{2}(2 d f)=7.537, p=0.023\right.$; Model 1.1 and 1.2 in Table S6), although not the one for duration $\left(\Delta \chi^{2}(2 d f)=4.682, p=0.096\right.$; Model 2.1 and 2.2 in Table S6).

To confirm that the observed differences in performance result from the differential effect of scoring type on effort, we additionally compare the timing, length, and code complexity of the first submission (Fig. S4 and Table S7). The differences between contestants in the challenges with absolute and relative 

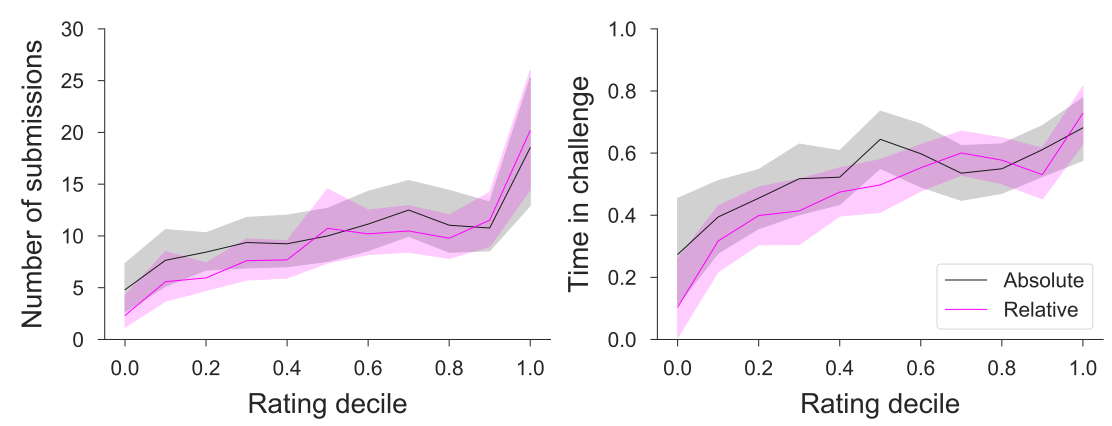

Figure 3: Low-rated individuals tend to make fewer submissions (left) and stay for shorter period out of the duration of the challenge (right) in challenges with relative scoring than in challenges with absolute scoring. The shaded area indicates $95 \%$ confidence intervals around the means, which are estimated over 954 stratum-individuals.

scoring are not statistically significant, indicating that the final outcomes are not driven by the contestants' a-priori expectations and dispositions but are the result of social comparison dynamics.

\section{Discussion}

This study uses a crossover quasi-experiment on data from the online crowdsourcing community Topcoder to investigate the causal effect of social comparison on the dispersion and predictability of individual performance. We find that when feedback is based on relative performance, low-rated participants reduce effort, while high-rated participants increase it. As a result, relative performance feedback leads to individual performance that is more extremely distributed in the group. We further found that, with social comparison, current performance becomes more predictable from prior performance, although the evidence for behavioral effects, beyond possible selection bias, is insufficient in this case. Over time, these effects could lead to a self-reinforcing loop that solidifies and even increases differences between bottom- and top-performers. Such emerging inequality is an undesirable outcome in organizations and communities that focus on learning, member satisfaction, and membership growth. In fact, our results are based on programming challenges on Topcoder that were not monetarily rewarded but specifically designed and organized to stimulate and engage the Topcoder community. Thus, our findings directly suggest that using evaluation and feedback focusing on relative performance should be avoided for such purposes.

The study contributes in several important ways to social science research. We situate our research question at the nexus of three relatively disconnected strands of inquiry: empirical research on the design and effects of contests from management science, empirical research on the effects of competition on group outcomes from behavioral economics, and social psychology theory on social comparison. Our major 
contribution is to introduce the problem of inequality and investigate the dispersion and predictability of performance as important group outcomes to consider in situations inducing competition due to social comparison. We argue that these outcomes have implications for the well-being and growth of organizations and communities, similarly to other manifestations of social and economic inequality [25].

Our second contribution is empirical - we provide evidence from an actual social setting that social comparison has behavioral effects even without financial incentives. Much of the research on contests coming from economics and management science has been framed and designed around the expected utility from winning a monetary prize [31, 32]. At the same time, empirical research on the behavioral effects of social comparison and competition rarely comes from outside the lab. Our results provide context and better understanding for the size and consequences of the effects we find. In the specific setting we study, individuals iteratively and independently improve their work in response to feedback about their performance, with the ultimate goal to outdo their peers and gain reputation and status. These aspects match many real situations we face in our daily lives: individual assessment and standardized testing for students, performance evaluations for employees, peer review for academics. Extrapolated to these settings, our findings indicate that, in the absence of opportunities for cooperation, Festinger's intuition about the equalizing force of social comparison is incorrect.

Our study also makes a methodological contribution. We devise and employ a two-step matching strategy that allows us to investigate our research question both at the group and the individual level. At the individual level, we use a quasi-experimental crossover design, drawing on a technique that is commonly employed in medicine and health research but relatively underused in social science. Although our approach was largely driven by context and data availability, it could certainly be transferred successfully to other research questions and social settings.

Despite the novel causal inference methods we employed, our study has several limitations. We employed matching in order to provide more accurate causal estimates but this made us disregard the majority of our data and narrow down the scope of our claims. For example, our findings do not necessarily transfer to contests that offer monetary rewards; financial considerations could overwhelm the subtle behavioral effects from social comparison we found but could also possibly interact with them.

Further, our research design is powerful when it comes to dealing with self-selection bias, but has limitations with respect to sample selection bias. We cannot be certain that the matched sample we study represents the Topcoder population accurately. At the same time, we are also doubtful that the Topcoder community is representative of society in general. However, neither of these pose a problem since we 
intend this study as a proof of concept, delivering evidence that a social phenomenon may occur, rather than providing an exact estimate of its impact on a population.

Still, our sophisticated matching techniques do not entirely preclude the possibility for confounding. Despite matching on multiple aspects, including the difficulty of the challenge and the complexity of the scoring procedure, it is still possible that relatively and absolutely scored challenges differ in respects that we have not captured and that may explain the observed effects on dispersion, predictability, and effort. We assumed that the only difference between the two types of challenges is the emphasis on social comparison but we cannot entirely preclude other subtle differences responsible for alternative behavioral mechanisms. As always, randomized field or lab experiments are the gold standard for causal claims, whenever they are possible and feasible.

In supplementary analyses, we also found out that our results concern only coders with prior experience on the platform and do not extend to first-time contestants. Assuming that first-timers randomly choose their first challenge, we tested if the performance, effort, and likelihood to participate again are different for those who happened to enter Topcoder with a relatively scored challenge versus absolutely scored challenge. However, the only statistically significant difference is that first-timers in relatively scored challenges tend to exit the contest faster than first-timers in absolutely scored challenges (Table S8). One possibility is that the effects on newcomers are exactly the same as for experienced Topcoder users but since we don't observe their ability, we cannot measure them. Of course, another possibility is that the effects do not extend to naïve participants and thus, our findings are restricted to a specific context and population.

With these caveats in mind, our results have concrete implications for the online platform we investigated, as well as for similar online and offline communities and organizations that are centered around the learning, engagement, and continuous participation of their members. Our findings suggest that feedback based on relative performance could increase effort and learning for high-ability individuals but have exactly the opposite effects on low-ability individuals. This could trigger a rich-get-richer-poor-get-poorer dynamic that increases performance differences in the group even further. Consequently, for communities and organizations that are focused on learning and member engagement, relying on social comparison for performance measurement could backfire when it comes to underachievers. These conclusions raise an alarm for a number of practices that are currently employed in educational and organizational settings.

For example, "grading on a curve", whereby course grades are determined in reference to others' performance, has been shown to increase average effort under some conditions [33, 34] but our research suggests that it might also increase the disparity in effort and performance between bottom achievers 
and top achievers. There is a trend to use leader boards and badges to gamify learning experiences but, complementing other empirical research [35, 36], our findings suggest that this innovation may not be equally beneficial for students of all skill levels. The practice to maintain class ranks in US high schools [37] can have similar and similarly undesirable effects. Along the same lines, some organizations employ a performance management practice known as "stack ranking", "forced ranking", or "vitality curve", whereby employees are rated against their coworkers [38]. Our research suggests that even if such performance feedback is not directly related to financial rewards and promotion, it can trigger a self-reinforcing process and lower effort further among bottom-performers. Social comparison and competition can negatively impact motivation and learning and organizations and communities that focus on equity and sustainability should not promote them.

\section{Materials and Methods}

\section{Data}

We combine data from two sources. First, we obtained detailed data from Topcoder on the contestants in each challenge and the submissions they made. For contestants, we know their Topcoder rating, the number of challenges in which they participated before, and their final score and rank in the challenge. For the submissions, we have the actual submitted code and know the time of submission, the programming language, and the provisional score achieved. We combine these data with manual classifications of the challenges along categories such as ease of entry, complexity of the scoring function, type of task, and scoring type. These classifications were computed from answers provided by coders in a dedicated challenge on Topcoder itself .

\section{Measures}

The classification by scoring type was provided by Topcoder users in a dedicated challenge on the platform. They were asked to mark the scoring type as absolute when "The score shows absolute performance of the solution on the test" and as relative when "The score shows performance relative to the performance of the other solutions".

We measure performance with the percentile rank by final score and the cyclomatic complexity of the code in the final submission. Cyclomatic complexity is a software complexity measure that is based on the decision structure of the code [39]. It quantifies the number of independent paths in the source code by 
counting the number of decision points, which occur at conditionals, logical expressions, and loops. We use cyclomatic complexity to measure how advanced and sophisticated the coder's solution is. However, very convoluted and inefficient code would also have high cyclomatic complexity. Indeed, we find that the correlation between the cyclomatic complexity of the code in the final submission and the coder's final rank percentile, although positive, can be quite low in some challenges (Fig. S1, right). Nevertheless, we also find that the measure typically increases with subsequent submissions (Fig. S1, left). Moreover, the cross-over experimental design we employ compares the difference in performance between the treatment and control within individuals. Essentially, we ignore individual differences in coding style and only focus on the change in the code complexity for each individual.

We measure effort with the number of code lines (disregarding comments) written by the contestant for the challenge. We calculate the number of code lines by summing the number of code lines in the first submission with the number of new or edited code lines in all subsequent submissions, given by the code file diffs (see SI). This measure does not differentiate between small edits, such as changing a variable name, and a major overhaul, such as rewriting the algorithm, but it generally captures the amount of work and attention involved. To confirm the robustness of the findings on effort, we additionally look at the number of submissions and the duration of the coder's participation in the challenge, expressed as a proportion of the challenge duration.

Finally, for ability, we use the coder's official Topcoder Marathon Match rating. Topcoder calculates this rating using a complex algorithm that evaluates the coder's actual performance in reference to the performance expected by their previous rating and accounts for how many previous challenges the coder has participated in and how volatile their performance in these previous challenges has been. It should be noted that this measure is not perfect since it is noisier for coders who have participated in fewer previous challenges on the platform. We mitigate for this limitation, however, by controlling for the number of previous challenges in the individual-level statistical models.

To investigate the dispersion of performance, we cannot use percentile ranks by final score since these always have a uniform distribution; similarly, we cannot use the absolute final scores since they are deliberately scaled in relatively scored challenges. Hence, we analyze the complexity of the final submitted code and at the group level, we estimate the Gini coefficient, while at the individual level, we simply predict it by ability. Similarly, for effort, we use the Gini coefficient for the total number of code lines written at the group level and predict the total number of code lines with ability at the individual level. The Gini coefficient is a dimensionless measure of statistical dispersion, most commonly used to quantify economic 
inequality. We present it here because it is easy to interpret: a Gini of 0 means that all participants have the same score, while a Gini of 1 - that all but one participant, the winner, have a score of 0 . However, our results replicate if we instead measure dispersion with the coefficient of variation, which is the ratio of the standard deviation to the mean.

To investigate the predictability of performance at the group level, we use the Spearman rank correlation between the contestants' percentile rank by final score and their percentile rank by Topcoder rating. At the individual level, we estimate the absolute difference between the percentile rank by final score and the percentile rank by Topcoder rating and subtract it from 1 in order to have higher values correspond to higher predictability.

\section{Experimental design}

\section{Coarsened exact matching}

We use coarsened exact matching to identify strata of challenges that are similar in all possible respects except for the scoring procedure. With coarsened exact matching, we first coarsen the matching variables $C$ to fewer meaningful categories $c(C)$ and then perform exact matching on $c(C)$ [40]. Subsequently, the data is sorted into strata of unique values in $c(C)$. Any stratum that does not include at least one observation for each level of the explanatory variable, i.e. scoring procedure, is then pruned. Finally, we pass the uncoarsened values $C$ of the covariates along for analysis. For any estimation that is carried out after the pruning process, we add weights that are based on the relative frequency of observations within strata. This step ensures that differences in the distribution of observations across strata do not distort the results [40].

We choose to match on all variables that might be correlated with the scoring type $X$ and any of the outcomes $Y$ : variables related to the size, duration, difficulty, reward structure, and task of the challenge. For most discrete data, we simply use the levels as the values for which the data must match. For continuous variables we select cut points to coarsen the data based on substantive judgement and an analysis of the variables' distributions. Table S1 summarizes the variables and the coarsened levels that we use for constructing the strata in the matching process.

To coarsen the variables for number of contestants, challenge duration, prize pool, and number of prizes, we started with an a priori expectation about meaningfully different categories (e.g., contests without monetary prizes vs. contests with top-three prizes vs. contests with multiple prizes) and adjusted it according to the observed distribution in our sample of challenges (for the same example, we settled on 0 
prizes, 1-5 prizes, and 8-10 prizes). For engagement barrier and scoring complexity, which are based on fivelevel Likert scale responses, we split between the categories "1-Strongly Agree" and "2-Agree" on the one hand, and the rest on the other. The decision how to coarsen the variables for contestants/registrants ratio and average contestant experience was mainly driven by the distributions of these variables. Specifically, we divided average contestant experience by tercile and split contestants/registrants ratio halfway through, with an additional category for very high values $\geq 0.9$.

After performing the matching procedure, we obtain a dataset of 52 challenges in 16 strata, with a reasonable covariate balance for the six coarsened variables (Fig. S2).

\section{Crossover quasi-experiment}

We first test for differences in the dispersion of performance, the predictability of performance, and the dispersion of effort in the challenges with relative scoring (treatment) compared to the challenges with absolute scoring (control). The challenge-level analyses, however, have limitations. On the one hand, they cannot account for possible self-selection into the treatment that we cannot control for with the challenge covariates we have. And on the other hand, they also hide the effect heterogeneity for differently able individuals that we expect. Hence, we next identify coders with measured ability and with observations for both scoring procedures in the same stratum. Doing this allows us to approximate a controlled crossover experiment, in which subjects are exposed to both the treatment and control and their outcomes are measured at each occasion.

After matching the challenges and identifying individuals with Topcoder rating who have at least one treatment and one control observation in one of the strata, we are left with 1,239 observations of 319 coders over 42 challenges in 12 strata; these coders made 12,914 successful code submissions altogether. Compared to the average contestant in the same challenge, our "subjects" are more experienced and higher rated; further, they make more submissions and perform better (Table S3). Nevertheless, in most cases, the observations in the matched data span the full range of values, giving us enough variability to make conclusions about a diverse set of individuals on Topcoder.

\section{Statistical models}

Since we are using pruned data, we cannot claim to measure the treatment effect on the whole population. Rather, the estimand in our statistical models is the local average treatment effect for the treated [40]. 


\section{Group-level models}

We use regression models to identify the effect of relative scoring on the dispersion of performance, the predictability of performance, and the dispersion of effort in the matched challenges. Since not all types of challenges are equally represented, we control for challenge-level covariates and weigh the observations by strata. We fit the model:

$$
Y_{j}=b_{0}+b_{1} X_{j}+b_{2} C_{j}+e_{j}
$$

where $X_{j}$ is the scoring type, $C_{j}$ are the uncoarsened values of the covariates we use for matching, and $e_{j}$ is a random error term for challenge $j$.

The measures of predictability and dispersion of effort and performance are strictly positive and bounded by 1 . Hence, we fit beta regression models; model diagnostics confirmed that the model fits are appropriate. If the variable included the values 0 and 1 , we rescaled it using the equation $y^{\prime}=$ $(y(N-1)+0.5) / N$, where $N$ is the sample size. We use $N=367$, which the total number of challenges in our data [41. The results from the group-level models are presented in Table S4.

\section{Individual-level models}

Our data are partially crossed since individuals are nested within different challenges but not all individuals are present in all of the challenges. Essentially, we have a non-balanced design with non-independent observations and we account for it by fitting mixed effects models with random intercepts for strata, challenges, and individuals [42], as well as weights by strata.

In the models, we include the coder's Topcoder rating $\left(Z_{i j}\right)$, which is a challenge-varying individuallevel variable. Additionally, we control for treatment ordering effects by including the number of challenges the coder has already participated in, which is another challenge-varying individual-level covariate $\left(P_{i j}\right)$. The following equation describes the general structure of our models:

$$
Y_{i j k}=b_{0}+K_{0 k}+J_{0 j}+I_{0 i}+b_{1} X_{j}+b_{2} Z_{i j}+b_{3} X_{j} Z_{i j}+b_{4} P_{i j}+e_{i j}
$$

where $K_{0 k}$ is the stratum random intercept, $J_{0 J}$ is the challenge random intercept, and $I_{0 i}$ is the individual random intercept. The interaction term between scoring type and coder rating helps to disentangle the different effects we expect on high-performers and low-performers. In practice, we model the relationship between rating and proximity to rating as quadric and the relationship between rating and 
code complexity and number of code lines as cubic. This decision is informed by the shape of the bivariate relation depicted in Figure 2 and the best model fit. These two criteria similarly inform our decisions about which terms to interact with scoring type. To test the effect of scoring type on the relationship between rating and performance/effort as a whole, we compare the models with and without treatment effects with the Chi-square difference test.

Our measurements of effort (number of code lines written) and performance (code complexity) are strictly positive and can be seen as a continuous representation of count variables. The variables are heavily skewed to the right and hence, we fit gamma regression models with a log link function [43, 44]. The measure of predictability is also positive but bounded by 1 and hence, we fit a beta regression model for proximity to rating, using the rescaling mentioned in the previous subsection with $N=29,075$, which is the total number of challenge contestants (but notice, not unique coders) in our data [41. The results from the individual-level models are presented in Table S5.

\section{Acknowledgements}

M.T., S.M., and O.V. acknowledge the generous support of the Volkswagen Foundation under Grant Ref. 92 173. The funders had no role in study design, data collection and analysis, decision to publish, or preparation of the manuscript. R.S. is funded by the Division of Research and Faculty Development at Harvard Business School.

\section{References}

[1] Festinger, L. A theory of social comparison processes. Human Relations 7, 117-140 (1954).

[2] Payne, B. K. The Broken Ladder: How Inequality Affects the Way We Think, Live, and Die (Viking, New York, 2017).

[3] Frank, R. H. The Darwin Economy: Liberty, Competition, and the Common Good (Princeton University Press, Princeton, NJ, 2012).

[4] Fliessbach, K. et al. Social comparison affects reward-related brain activity in the human ventral striatum. Science 318, 1305-1308 (2007).

[5] Garcia, S. M., Tor, A. \& Schiff, T. M. The psychology of competition: A social comparison perspective. Perspectives on Psychological Science 8, 634-650 (2013). 
[6] Dechenaux, E., Kovenock, D. \& Sheremeta, R. M. A survey of experimental research on contests, all-pay auctions and tournaments. Experimental Economics 18, 609-669 (2015).

[7] Connelly, B. L., Tihanyi, L., Crook, T. R. \& Gangloff, K. A. Tournament theory: Thirty years of contests and competitions. Journal of Management 40, 16-47 (2014).

[8] Messick, D. M. \& McClintock, C. G. Motivational bases of choice in experimental games. Journal of Experimental Social Psychology 4, 1-25 (1968).

[9] Sheremeta, R. M. Experimental comparison of multi-stage and one-stage contests. Games and Economic Behavior 68, 731-747 (2010).

[10] Mago, S. D., Samak, A. C. \& Sheremeta, R. M. Facing your opponents: Social identification and information feedback in contests. Journal of Conflict Resolution 60, 459-481 (2016).

[11] Dickinson, D. L. \& Isaac, R. M. Absolute and relative rewards for individuals in team production. Managerial and Decision Economics 19, 299-310 (1998).

[12] Cason, T. N., Masters, W. A. \& Sheremeta, R. M. Entry into winner-take-all and proportional-prize contests: An experimental study. Journal of Public Economics 94, 604-611 (2010).

[13] Wright, B. D. The economics of invention incentives: Patents, prizes, and research contracts. American Economic Review 73, 691-707 (1983).

[14] Travis, J. Science by the masses. Science 319, 1750-1752 (2008).

[15] Lakhani, K. R. et al. Prize-based contests can provide solutions to computational biology problems. Nature Biotechnology 31, 108-111 (2013).

[16] Liu, G., Lin, C. \& Xin, Z. The effects of within- and between-group competition on trust and trustworthiness among acquaintances. PLOS ONE 9, e103074 (2014).

[17] Barker, J. L. \& Barclay, P. Local competition increases people's willingness to harm others. Evolution and Human Behavior 37, 315-322 (2016).

[18] West, S. A. et al. Cooperation and the scale of competition in humans. Current Biology 16, 1103-1106 (2006).

[19] Barclay, P. \& Stoller, B. Local competition sparks concerns for fairness in the ultimatum game. Biology Letters 10, 20140213 (2014). 
[20] Harbring, C. \& Irlenbusch, B. Sabotage in tournaments: Evidence from a laboratory experiment. Management Science 57, 611-627 (2011).

[21] Charness, G., Masclet, D. \& Villeval, M. C. The dark side of competition for status. Management Science 60, 38-55 (2013).

[22] Chowdhury, S. M. \& Grtler, O. Sabotage in contests: A survey. Public Choice 164, 135-155 (2015).

[23] Van de Werfhorst, H. G. \& Mijs, J. J. Achievement Inequality and the Institutional Structure of Educational Systems: A Comparative Perspective. Annual Review of Sociology 36, 407-428 (2010).

[24] Stainback, K., Tomaskovic-Devey, D. \& Skaggs, S. Organizational Approaches to Inequality: Inertia, Relative Power, and Environments. Annual Review of Sociology 36, 225-247 (2010).

[25] Bapuji, H., Ertug, G. \& Shaw, J. D. Organizations and societal economic inequality: A review and way forward. ANNALS (2019).

[26] Dohmen, T. \& Falk, A. Performance pay and multidimensional sorting: Productivity, preferences, and gender. American Economic Review 101, 556-590 (2011).

[27] Chen, K.-P. Sabotage in promotion tournaments. The Journal of Law, Economics, and Organization 19, 119-140 (2003).

[28] Callan, M. J., Shead, N. W. \& Olson, J. M. Personal relative deprivation, delay discounting, and gambling. Journal of Personality and Social Psychology 101, 955-973 (2011).

[29] Garcia, S. M., Tor, A. \& Gonzalez, R. Ranks and Rivals: A Theory of Competition. Personality and Social Psychology Bulletin 32, 970-982 (2006).

[30] Archak, N. Money, glory and cheap talk: Analyzing strategic behavior of contestants in simultaneous crowdsourcing contests on TopCoder.com. In Proceedings of the 19th International Conference on World Wide Web, WWW '10, 21-30 (ACM, New York, NY, USA, 2010). Event-place: Raleigh, North Carolina, USA.

[31] Boudreau, K. J., Lacetera, N. \& Lakhani, K. R. Incentives and problem uncertainty in innovation contests: An empirical analysis. Management Science 57, 843-863 (2011). 
[32] Boudreau, K., Helfat, C. E., Lakhani, K. R. \& Menietti, M. E. Field evidence on individual behavior and performance in rank-order tournaments. Harvard Business School Working Paper Series \# 13-016 (2012).

[33] Becker, W. E. \& Rosen, S. The learning effect of assessment and evaluation in high school. Economics of Education Review 11, 107-118 (1992).

[34] Andreoni, J. \& Brownback, A. All pay auctions and group size: Grading on a curve and other applications. Journal of Economic Behavior $\&$ Organization 137, 361-373 (2017).

[35] Domínguez, A. et al. Gamifying learning experiences: Practical implications and outcomes. Computers E Education 63, 380-392 (2013).

[36] Hanus, M. D. \& Fox, J. Assessing the effects of gamification in the classroom: A longitudinal study on intrinsic motivation, social comparison, satisfaction, effort, and academic performance. Computers E Education 80, 152-161 (2015).

[37] Lang, D. M. Class rank, GPA, and valedictorians: How high schools rank students. American Secondary Education 35, 36-48 (2007).

[38] Stewart, S. M., Gruys, M. L. \& Storm, M. Forced distribution performance evaluation systems: Advantages, disadvantages and keys to implementation. Journal of Management 8 Organization 16, 168-179 (2010).

[39] McCabe, T. A complexity measure. IEEE Transactions on Software Engineering SE-2, 308-320 (1976).

[40] Iacus, S. M., King, G. \& Porro, G. Causal inference without balance checking: Coarsened exact matching. Political Analysis 20, 1-24 (2012).

[41] Smithson, M. \& Verkuilen, J. A better lemon squeezer? Maximum-likelihood regression with betadistributed dependent variables. Psychological Methods 11, 54-71 (2006).

[42] Barr, D. J., Levy, R., Scheepers, C. \& Tily, H. J. Random effects structure for confirmatory hypothesis testing: Keep it maximal. Journal of Memory and Language 68, 255-278 (2013).

[43] Faraway, J. J. Extending the Linear Model with R: Generalized Linear, Mixed Effects and Nonparametric Regression Models (Chapman and Hall/CRC, Boca Raton, 2005), 1 edition edn. 
[44] Brooks, M. E. et al. glmmTMB balances speed and flexibility among packages for zero-inflated generalized linear mixed modeling. The $R$ Journal 9, 378-400 (2017). 


\title{
Supplementary materials for:
}

\section{Social comparison increases the dispersion and predictability of effort}

\author{
and performance
}

Milena Tsvetkova, Sebastian Müller, Oana Vuculescu, Haylee Ham, and Rinat Sergeev

\section{Supplementary Text}

\section{Data}

\section{Data collection}

For each challenge, we obtained data from Topcoder on the number of registrants, the number of contestants, an estimate of the duration of the challenge, and an estimate of the average rating of the contestants based on their performance in prior challenges. In addition, we have manual classifications of the challenges along a number of less straightforward categories - for example, ease of entry, the complexity of the scoring function, the type of the task, and the type of scoring. These classifications were computed from answers provided by coders in a dedicated challenge on Topcoder itself (https: //community. topcoder . com/longcontest/?module=ViewProblemStatement\&rd=17094\&pm=14852).

For each contestant in a challenge, we know their Topcoder rating, the number of challenges they participated in before, and their final score and rank in the challenge. To calculate a coder's rating, Topcoder uses a complex formula that considers the coder's actual performance in reference to their expected performance given all contestants' previous rating, the volatility of performance, and the number of previous contests (https://community.topcoder.com/longcontest/?module=Static\&d1=support\&d2=ratings).

Additionally, for each submission the contestant made in the challenge, we have the actual submitted code and know the time of submission, the programming language, and the provisional score achieved. 


\section{Data cleaning}

Each challenge poses a well-defined problem and has a unique leader board and prize structure. However, sometimes different challenges may be based on the same problem or challenges may be complementary, with each of them covering one aspect of a larger problem, often with an increasing level of difficulty. To avoid outlier effects in our analyses, we excluded 111 challenges that were based on a single problem (these presented a controlled experiment on the platform), leaving us with 256 challenges based on 214 unique problems. We additionally removed any challenge that had fewer than 10 contestants (5 challenges). The final set of 52 matched challenges corresponds to 49 unique problems.

When analyzing individual submissions we ignored 0-point submissions. These occur extremely often in the data and could be explained with minor bugs in the code that break the provisional scoring system. They are thus not indicative of effort in the same way that a new code revision is.

Similarly, when analyzing contestants in a challenge, we only considered individuals who made at least one non-zero submission. Although any coder who made a submission, whether successful or not, was considered a contestant and attributed a new rating as a result of their rank in the challenge, it is impossible to discern whether coders with only 0-point submissions made consistent effort or simply tested the system without being aware of the repercussions. Consistent with our decision to ignore 0-point submissions, we considered that these individuals made 0 successful submissions and, in effect, did not participate.

To calculate the Gini coefficients for code complexity and the Spearman rank correlation between rating and score percentile ranks, we require at least 8 non-missing observations. New contestants who have just joined the platform by definition lack Topcoder rating. Since challenges that took place soon after Topcoder started contain mainly new platform members, the number of observations that we end up analyzing when rating is involved is actually lower. Specifically, Model 2 in Table S4 and the individual-level models in Table $\mathrm{S} 8$ are based on 42 instead of 52 challenges. The analyses involving cyclomatic complexity and file diffs also contain a number of missing values due to the algorithms failing to run on the submitted code.

\section{Measures}

\section{Scoring type}

The classification by scoring type was provided by Topcoder users in a dedicated challenge on the platform. They were asked to mark the scoring type as absolute when "The score shows absolute performance of the solution on the test" and as relative when "The score shows performance relative to the performance of the other solutions". Below we provide two examples of how the scoring description might look like in 
each case.

Stratum 5, Absolute scoring: "You will score 100 points for each coal that is dumped into a shaft. 1 point is deducted for each time step that you use, this relates to the running costs of your trucks. You may only use a maximum of 10000 time steps. All time steps greater than 10000 will be ignored. Your score for a test case will be $\operatorname{Max}(0,100 *($ Coal gathered) (Simulation steps used)). Any invalid move will result in a zero score. Your overall score will be the sum of your scores over all test cases."

Stratum 5, Relative scoring: "Your score for an individual test case will be the BEST/YOU. Where YOU is the number of moves returned by your solution and BEST is the lowest number of moves returned by any of the competitors. Any kind of failure (invalid return, exceeding time/memory limit, moves not resulting in connected groups) will result in 0 score for that test. Your total score is simply the sum of scores for every test case."

Stratum 12, Absolute scoring: "The score for a test case will be $100 * \max (0,1$ - (number of shifts in your return) / (SZ*SZ)). Invalid returns or returns which result in non-connected group of white tiles result in 0 score for that test case. The overall score is calculated as a sum of individual scores for all test cases."

Stratum 12, Relative scoring: "Your score for an individual test case will be the sum of sizes of your returned polygons. If your return has invalid format or specifies any invalid polygons, your score for the test case will be 0 . Your overall score will be calculated in the following way: for each test case where your score is not 0 , you get 1 point for each competitor you beat on this test case (i.e., your score on a test case is larger than this competitor's score) and 0.5 points for each competitor you tie with (a tie with yourself is not counted); finally, the sum of points is divided by (the number of competitors - 1)."

\section{Code complexity}

The complexity of the source code was measured using cyclomatic complexity, as introduced by Thomas J. McCabe [1]. This software complexity measure uses the control graph of the code in order to determine the maximum number of linearly independent paths through the code. It is based on the idea that the complexity of the code is independent of its length and can be measured instead with the number of decision points. 
We calculated cyclomatic complexity with the Python package Lizard [2]. Lizard is a cyclomatic complexity analyzer that can be applied to all of the major programming languages used in the Topcoder source code files, including $\mathrm{C}++, \mathrm{C} \#$, Java, and Python. The software increments the complexity measure by one unit each time it finds a condition in a function. For example, the Python conditions that the algorithm looks for are "if", "for", "while", "and", "or", "elif", "except", and "finally". Each of these conditions marks the creation of another linearly independent path through the code and therefore increases the complexity by one. The scores are calculated for each function in the source code and then summed to give the final measure.

\section{Total number of code lines written}

To quantify effort, we estimate the total number of lines the coder wrote for the challenge. To do this, we sum over the number of new code lines inserted with every submission. We first selected all submissions which received a non-zero score (solutions which fail to compile receive a score of zero). We then cleaned up all comments in the code files, alongside trailing and leading spaces. Finally, we used a matlab implementation of the diff algorithm to count the insertions in each submission compared to the previous one. The diff utility is a common tool to compare two sets of data (e.g. files) line by line [3]. This differentiates it, for example, from the edit distance, another popular text comparison measure, which executes the comparison by character. The particular implementation of the diff utility we used (SimpleDiff) was developed by Paul Butler and relies on the Ratcliff/Obershelp algorithm to solve the longest common subsequence problem in order to determine the smallest set of deletions and insertions to create one set from the other [4].

\section{References}

[1] McCabe, T. A complexity measure. IEEE Transactions on Software Engineering SE-2, 308-320 (1976).

[2] Yin, T. Lizard: A simple code complexity analyser. Python package version 1.16.6. (2019). URL https://github.com/terryyin/lizard. Retrieved from: https://github.com/terryyin/lizard.

[3] Hunt, J. W. \& MacIlroy, M. D. An Algorithm for Differential File Comparison (Bell Laboratories Murray Hill, 1976).

[4] Ratcliff, J. W. \& Metzener, D. E. Pattern-matching-the gestalt approach. Dr Dobbs Journal 13, 46 (1988). 

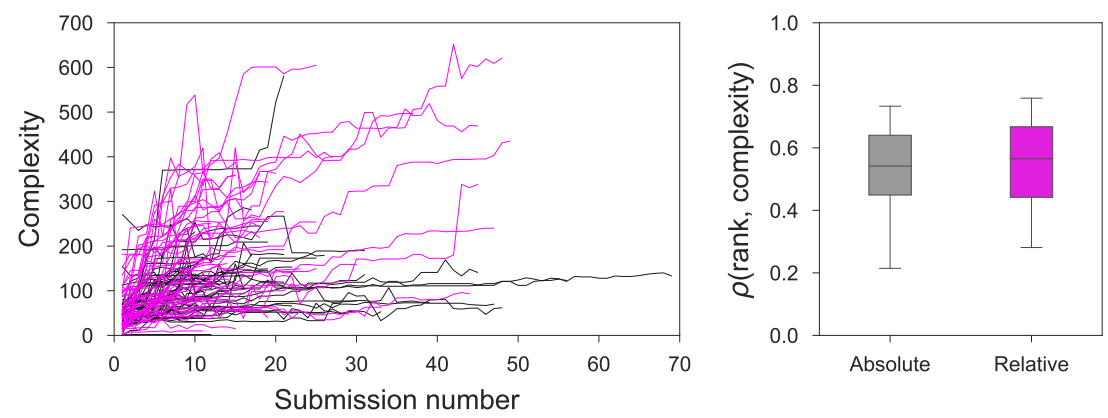

Figure S1: The cyclomatic complexity of the source code is a suitable measure of performance because it generally increases in subsequent submissions (left) and is correlated with rank percentile by final score in the challenge (right). The left plot shows the cyclomatic complexity of the submitted code for each subsequent submission for 100 contestants who made at least 10 submissions, randomly selected from the sample of matched individuals. The right plot shows boxplots of the Spearman rank correlation between the cyclomatic complexity of the code in the final submission and the rank percentile by final score in the 52 matched challenges.
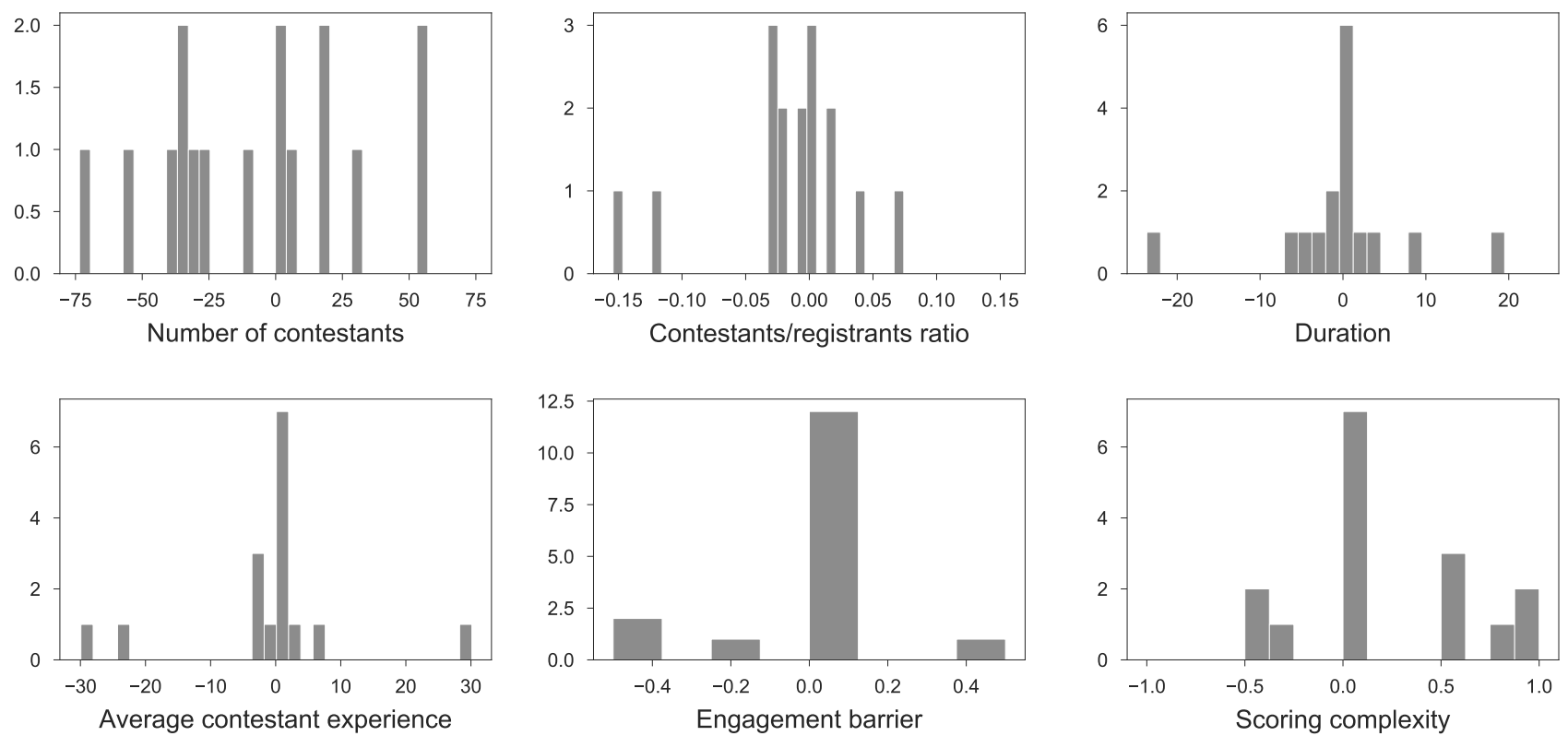

Figure S2: Covariate balance for the coarsened variables used for the coarsened exact matching. The figure shows the histogram of the difference in means between the relatively scored and the absolutely scored challenges in the 16 matched strata. A positive value means that the relatively scored challenges in the particular stratum have a higher value for this covariate than the absolutely scored challenges in that stratum; the converse holds for a negative value. 

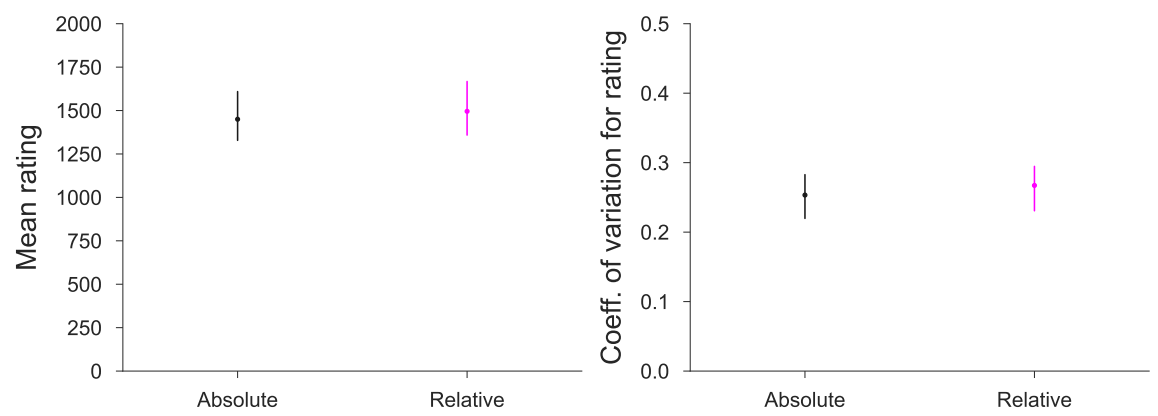

Figure S3: Participants in challenges with relative scoring have slightly higher (left) and more widely dispersed (right) Topcoder ratings than participants in challenges with absolute scoring. Error bars indicate $95 \%$ confidence intervals around the means, which are estimated over the matched challenge strata.
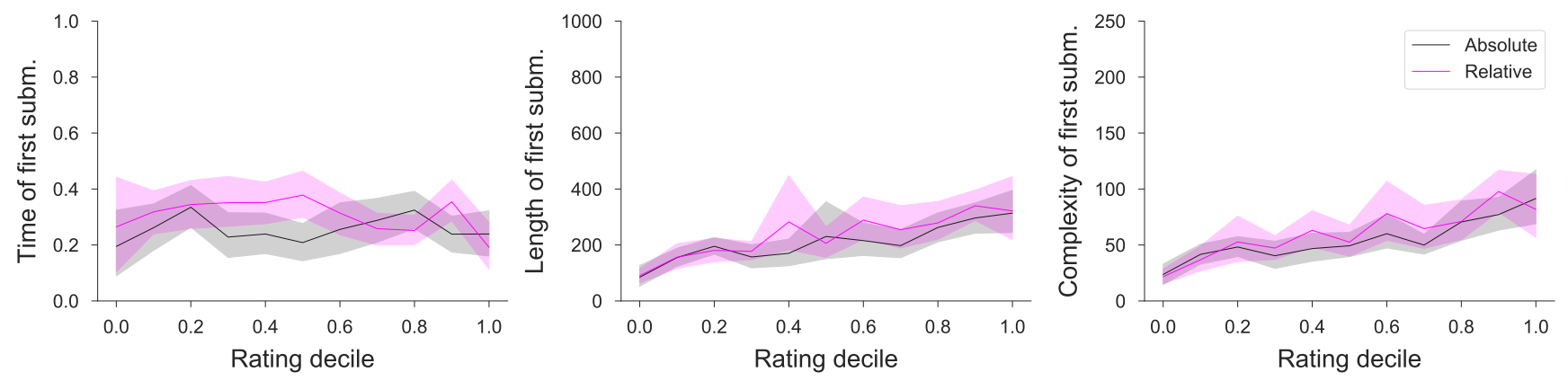

Figure S4: There are no significant differences in the timing (left), length(middle), and complexity(right) of the first submission between relative and absolute challenges. Error bars and shaded areas indicate $95 \%$ confidence intervals around the means, which are estimated over 954 stratum-individuals. 
Table S1: Description of the challenge variables used for the coarsened exact matching $(\mathrm{N}=256)$.

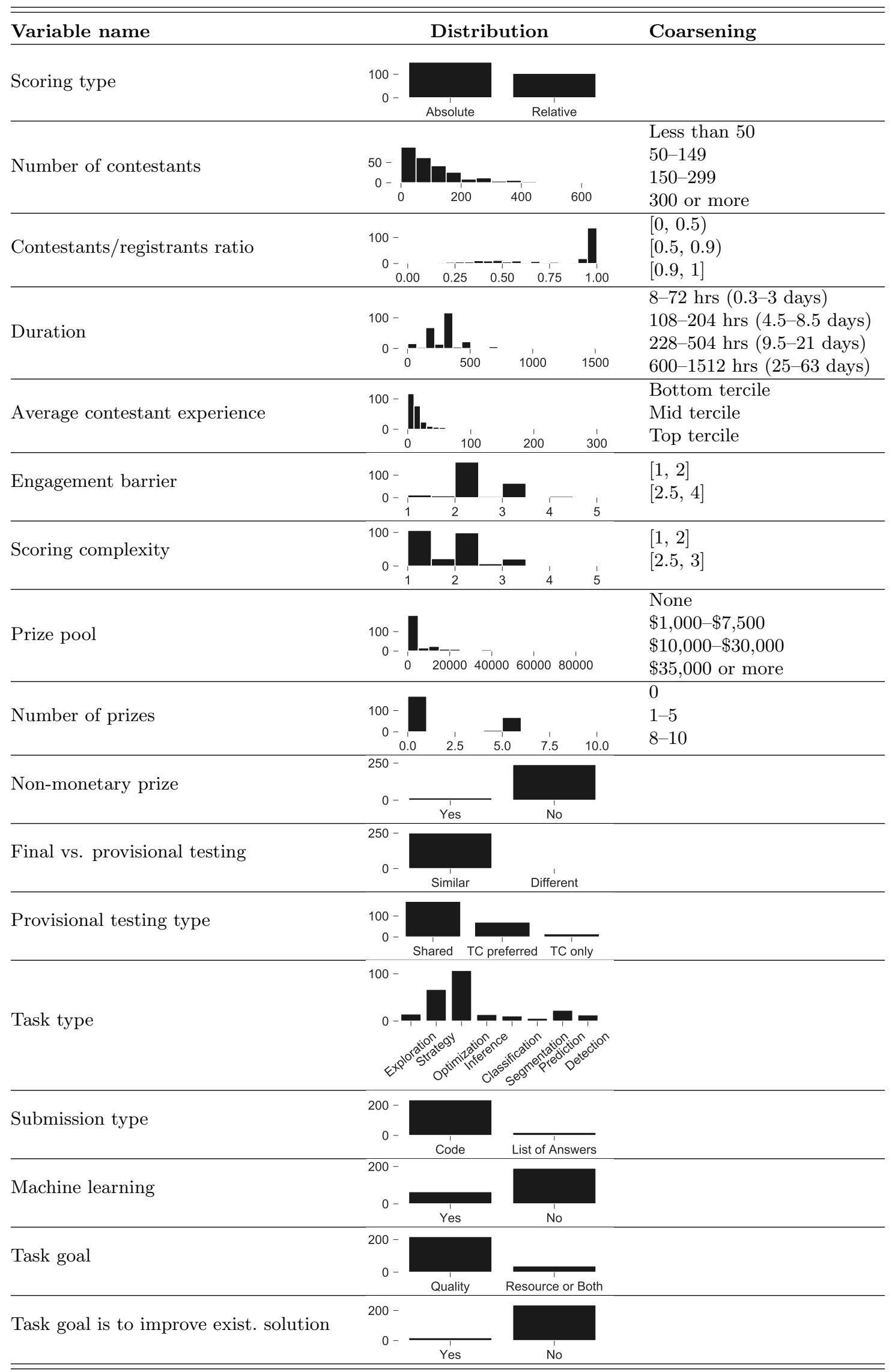


Table S2: Description of the matched challenges $(\mathrm{N}=52)$.

\begin{tabular}{|c|c|c|c|c|c|}
\hline Variable name & Category & Mean / Freq. & St. Dev. & Min & Max \\
\hline \multirow[t]{2}{*}{ Scoring type } & Absolute & $40.38 \%(21)$ & & & \\
\hline & Relative & $59.62 \%(31)$ & & & \\
\hline Number of contestants & & 122.52 & 80.33 & 10 & 293 \\
\hline Contestants/registrants ratio & & 0.77 & 0.31 & 0.14 & 1.00 \\
\hline Duration & & 289.63 & 96.09 & 8 & 355 \\
\hline Average contestant experience & & 29.50 & 50.30 & 1.16 & 221.53 \\
\hline Engagement barrier & & 1.89 & 0.29 & 1 & 2 \\
\hline Scoring complexity & & 1.32 & 0.44 & 1 & 2 \\
\hline Prize pool & & 0 & 0 & 0 & 0 \\
\hline Number of prizes & & 0 & 0 & 0 & 0 \\
\hline Non-monetary prize & No & $100 \%$ & & & \\
\hline Final vs. provisional testing & Similar & $100 \%$ & & & \\
\hline \multirow[t]{2}{*}{ Provisional testing type } & Shared & $92.31 \%(48)$ & & & \\
\hline & TC only & $7.69 \%(4)$ & & & \\
\hline \multirow[t]{2}{*}{ Task type } & Optimization & $67.31 \%(35)$ & & & \\
\hline & Strategy & $32.69 \%(17)$ & & & \\
\hline Submission type & Code & $100 \%$ & & & \\
\hline Machine learning & No & $100 \%$ & & & \\
\hline \multirow[t]{2}{*}{ Task goal } & Quality & $96.15 \%(50)$ & & & \\
\hline & Resource or both & $3.85 \%(2)$ & & & \\
\hline Task goal is improve exist. sol. & No & $100 \%$ & & & \\
\hline
\end{tabular}

Table S3: Description of the contestants in the matched challenges.

\begin{tabular}{|c|c|c|c|c|c|c|c|c|}
\hline \multirow[t]{2}{*}{ Variable name } & \multicolumn{4}{|c|}{ All $(\mathrm{N}=5,916)$} & \multicolumn{4}{|c|}{ In both scoring types $(\mathrm{N}=1,239)$} \\
\hline & Mean & St. Dev. & Min & $\operatorname{Max}$ & Mean & St. Dev. & Min & Max \\
\hline Number of unique individuals & 2774 & & & & 319 & & & \\
\hline Rating $^{1}$ & 0.506 & 0.288 & 0.004 & 1 & 0.565 & 0.290 & 0.004 & 1 \\
\hline Number of prev. challenges & 8.204 & 13.175 & 0 & 125 & 19.718 & 18.345 & 1 & 125 \\
\hline Code complexity $^{2}$ & 117.180 & 115.361 & 1 & 1476 & 147.124 & 128.391 & 1 & 1208 \\
\hline Proximity to rating $^{1}$ & 0.813 & 0.162 & 0.062 & 1 & 0.830 & 0.151 & 0.181 & 1 \\
\hline Total code lines written ${ }^{3}$ & 783.165 & 1120.635 & 3 & 37076 & 1006.899 & 1123.781 & 3 & 20701 \\
\hline Number of submissions & 7.864 & 9.364 & 1 & 162 & 10.423 & 11.312 & 1 & 147 \\
\hline
\end{tabular}

Note:

1. Based on $\mathrm{N}=4,158$ observations for all.

2. Based on $\mathrm{N}=5,577$ observations for all and $\mathrm{N}=1,195$ for individuals in both scoring types.

3. Based on $\mathrm{N}=5,113$ observations for all and $\mathrm{N}=1,123$ for individuals in both scoring types. 
Table S4: Results for performance dispersion, performance predictability, and effort dispersion at the group level.

\begin{tabular}{|c|c|c|c|}
\hline & $\begin{array}{c}\text { Gini complexity } \\
(1) \\
\end{array}$ & $\begin{array}{c}\rho \text { (rating, score) } \\
(2)\end{array}$ & $\begin{array}{c}\text { Gini code lines } \\
(3) \\
\end{array}$ \\
\hline Relative scoring & $\begin{array}{c}0.123 \\
(0.087)\end{array}$ & $\begin{array}{c}0.293^{*} \\
(0.147)\end{array}$ & $\begin{array}{c}0.005 \\
(0.068)\end{array}$ \\
\hline Number of contestants & $\begin{array}{c}0.001 \\
(0.001)\end{array}$ & $\begin{array}{l}-0.001 \\
(0.001)\end{array}$ & $\begin{array}{c}0.001 \\
(0.001)\end{array}$ \\
\hline Contestants/registrants ratio & $\begin{array}{c}0.074 \\
(0.164)\end{array}$ & $\begin{array}{l}1.082^{* *} \\
(0.355)\end{array}$ & $\begin{array}{c}0.041 \\
(0.130)\end{array}$ \\
\hline Duration & $\begin{array}{c}0.003^{* * *} \\
(0.001)\end{array}$ & $\begin{array}{c}-0.0004 \\
(0.001)\end{array}$ & $\begin{array}{c}0.004^{* * *} \\
(0.001)\end{array}$ \\
\hline Average contestant experience & $\begin{array}{l}-0.001 \\
(0.001)\end{array}$ & $\begin{array}{c}-0.054^{* * *} \\
(0.013)\end{array}$ & $\begin{array}{c}-0.003^{* *} \\
(0.001)\end{array}$ \\
\hline Engagement barrier & $\begin{array}{l}-0.162 \\
(0.214)\end{array}$ & $\begin{array}{c}0.015 \\
(0.421)\end{array}$ & $\begin{array}{l}-0.225 \\
(0.168)\end{array}$ \\
\hline Scoring complexity & $\begin{array}{c}0.140 \\
(0.127)\end{array}$ & $\begin{array}{l}0.451^{*} \\
(0.204)\end{array}$ & $\begin{array}{c}0.172 \\
(0.099)\end{array}$ \\
\hline TC only provisional testing & $\begin{array}{l}0.777^{* *} \\
(0.266)\end{array}$ & & $\begin{array}{l}0.621^{* *} \\
(0.209)\end{array}$ \\
\hline Optimization task & $\begin{array}{l}-0.014 \\
(0.121)\end{array}$ & $\begin{array}{c}0.272 \\
(0.183)\end{array}$ & $\begin{array}{l}-0.120 \\
(0.099)\end{array}$ \\
\hline Targets quality & $\begin{array}{l}0.982^{* *} \\
(0.340)\end{array}$ & & $\begin{array}{l}0.700^{* *} \\
(0.266)\end{array}$ \\
\hline Constant & $\begin{array}{c}-2.483^{* * *} \\
(0.691)\end{array}$ & $\begin{array}{l}-0.355 \\
(0.916)\end{array}$ & $\begin{array}{c}-1.841^{* * *} \\
(0.538)\end{array}$ \\
\hline $\begin{array}{l}\text { Observations } \\
\text { Pseudo } \mathrm{R}^{2} \\
\text { Log Likelihood }\end{array}$ & $\begin{array}{c}49 \\
0.592 \\
62.936\end{array}$ & $\begin{array}{c}42 \\
0.530 \\
37.588\end{array}$ & $\begin{array}{c}47 \\
0.718 \\
70.649\end{array}$ \\
\hline
\end{tabular}

Note: Coefficients and standard errors (in brackets) for: (1) beta regression for the Gini coefficient for the cyclomatic complexity of the code in the final submission; (2) beta regression for the Spearman rank correlation coefficient between contestants' percentile rank by current Topcoder rating and percentile rank by final score in the challenge; (3) beta regression for the Gini coefficient for the total code lines written for the challenge. The models include weights by stratum and control for the matching variables that vary in the region of common support. ${ }^{*} \mathrm{p}<0.05 ;{ }^{* *} \mathrm{p}<0.01 ;{ }^{* * *} \mathrm{p}<0.001$ 
Table S5: Results for performance, performance predictability, and effort at the individual level.

\begin{tabular}{|c|c|c|c|c|c|c|}
\hline & \multicolumn{2}{|c|}{ Code complexity } & \multicolumn{2}{|c|}{ Proximity to rating } & \multicolumn{2}{|c|}{ Total code lines } \\
\hline & $(1.1)$ & $(1.2)$ & $(2.1)$ & $(2.2)$ & $(3.1)$ & $(3.2)$ \\
\hline Relative scoring & & $\begin{array}{l}-0.189 \\
(0.166)\end{array}$ & & $\begin{array}{c}0.201 \\
(0.108)\end{array}$ & & $\begin{array}{c}-0.269^{*} \\
(0.130)\end{array}$ \\
\hline Relative scoring $\times$ Rating & & $\begin{array}{l}1.480^{* *} \\
(0.544)\end{array}$ & & $\begin{array}{c}-0.349^{*} \\
(0.176)\end{array}$ & & $\begin{array}{l}0.405^{* *} \\
(0.148)\end{array}$ \\
\hline Relative scoring $\times$ Rating $^{2}$ & & $\begin{array}{c}-1.171^{*} \\
(0.495)\end{array}$ & & & & \\
\hline Rating & $\begin{array}{c}4.354^{* * *} \\
(0.882)\end{array}$ & $\begin{array}{c}3.656^{* * *} \\
(0.176)\end{array}$ & $\begin{array}{c}-1.792^{* * *} \\
(0.384)\end{array}$ & $\begin{array}{c}-1.575^{* * *} \\
(0.397)\end{array}$ & $\begin{array}{c}5.340^{* * *} \\
(1.046)\end{array}$ & $\begin{array}{c}5.307^{* * *} \\
(1.045)\end{array}$ \\
\hline Rating $^{2}$ & $\begin{array}{c}-6.801^{* * *} \\
(1.933)\end{array}$ & $\begin{array}{c}-6.477^{* * *} \\
(1.950)\end{array}$ & $\begin{array}{c}2.431^{* * *} \\
(0.355)\end{array}$ & $\begin{array}{c}2.420^{* * *} \\
(0.355)\end{array}$ & $\begin{array}{c}-8.260^{* * *} \\
(2.299)\end{array}$ & $\begin{array}{c}-8.675^{* * *} \\
(2.300)\end{array}$ \\
\hline Rating $^{3}$ & $\begin{array}{c}4.043^{* * *} \\
(1.227)\end{array}$ & $\begin{array}{c}4.271^{* * *} \\
(1.225)\end{array}$ & & & $\begin{array}{l}4.673^{* *} \\
(1.467)\end{array}$ & $\begin{array}{c}4.932^{* * *} \\
(1.467)\end{array}$ \\
\hline Number of prev. challenges & $\begin{array}{l}-0.001 \\
(0.002)\end{array}$ & $\begin{array}{l}-0.001 \\
(0.002)\end{array}$ & $\begin{array}{c}0.004^{* *} \\
(0.002)\end{array}$ & $\begin{array}{l}0.004^{*} \\
(0.002)\end{array}$ & $\begin{array}{l}-0.002 \\
(0.002)\end{array}$ & $\begin{array}{l}-0.002 \\
(0.002)\end{array}$ \\
\hline Constant & $\begin{array}{c}3.863^{* * *} \\
0.139\end{array}$ & $\begin{array}{c}3.946^{* * *} \\
(0.169)\end{array}$ & $\begin{array}{c}1.544^{* * *} \\
(0.111)\end{array}$ & $\begin{array}{c}1.426^{* * *} \\
(0.128)\end{array}$ & $\begin{array}{c}5.476^{* * *} \\
(0.155)\end{array}$ & $\begin{array}{c}5.605^{* * *} \\
(0.170)\end{array}$ \\
\hline Observations & \multicolumn{2}{|c|}{1188} & \multicolumn{2}{|c|}{1239} & \multicolumn{2}{|c|}{1025} \\
\hline Individuals & \multicolumn{2}{|c|}{308} & \multicolumn{2}{|c|}{319} & \multicolumn{2}{|c|}{279} \\
\hline Challenges & \multicolumn{2}{|c|}{42} & \multicolumn{2}{|c|}{42} & \multicolumn{2}{|c|}{40} \\
\hline Strata & \multicolumn{2}{|c|}{12} & \multicolumn{2}{|c|}{12} & \multicolumn{2}{|c|}{11} \\
\hline Individual-level variance & 0.138 & 0.136 & 0.028 & 0.028 & 0.223 & 0.221 \\
\hline Challenge-level variance & 0.082 & 0.073 & 0.000 & 0.000 & 0.050 & 0.046 \\
\hline Stratum-level variance & 0.031 & 0.030 & 0.002 & 0.002 & 0.027 & 0.027 \\
\hline Log Likelihood & -6752 & -6747 & 1040 & 1042 & -7821 & -7817 \\
\hline $\mathrm{AIC}$ & 13523 & 13517 & -2063 & -2063 & 15659 & 15656 \\
\hline$\Delta \chi^{2}$ & \multicolumn{2}{|c|}{$11.532^{* *}(3 \mathrm{df})$} & \multicolumn{2}{|c|}{$3.974(2 \mathrm{df})$} & \multicolumn{2}{|c|}{$7^{6.633}{ }^{*}(2 \mathrm{df})$} \\
\hline
\end{tabular}

Note: Coefficients and standard errors (in brackets) for: (1) mixed effects gamma regression for the cyclomatic complexity of the code in the final submission; (2) mixed effects beta regression for the proximity between the coder's challenge-specific percentile rank by Topcoder rating and their percentile rank by final score in the challenge; (3) mixed effects gamma regression for the total number of code lines the coder wrote in the challenge. The models include weights by stratum and control for treatment ordering effects using the number of previous challenges the coder has participated in. The models also include random intercepts by individual, challenge, and stratum. ${ }^{*} \mathrm{p}<0.05 ;{ }^{* *} \mathrm{p}<0.01 ;{ }^{* * *} \mathrm{p}<0.001$ 
Table S6: Results for effort at the individual level using alternative operationalizations for effort.

\begin{tabular}{|c|c|c|c|c|}
\hline & \multicolumn{2}{|c|}{ Num. submissions } & \multicolumn{2}{|c|}{ Time in challenge } \\
\hline & $(1.1)$ & $(1.2)$ & $(2.1)$ & $(2.2)$ \\
\hline Relative scoring & & $\begin{array}{c}-0.292^{* *} \\
(0.109)\end{array}$ & & $\begin{array}{l}-0.341 \\
(0.194)\end{array}$ \\
\hline Relative scoring $\times$ Rating & & $\begin{array}{c}0.338^{*} \\
(0.140)\end{array}$ & & $\begin{array}{c}0.531^{*} \\
(0.247)\end{array}$ \\
\hline Rating & $\begin{array}{c}4.109^{* * *} \\
(1.007)\end{array}$ & $\begin{array}{c}4.009^{* * *} \\
(1.007)\end{array}$ & $\begin{array}{c}6.898^{* * *} \\
(1.557)\end{array}$ & $\begin{array}{c}6.573^{* * *} \\
(1.561)\end{array}$ \\
\hline Rating $^{2}$ & $\begin{array}{c}-6.834^{* *} \\
(2.206)\end{array}$ & $\begin{array}{c}-7.058^{* *} \\
(2.207)\end{array}$ & $\begin{array}{c}-10.520^{* *} \\
(3.445)\end{array}$ & $\begin{array}{c}-10.540^{* *} \\
(3.443)\end{array}$ \\
\hline Rating $^{3}$ & $\begin{array}{l}3.879^{* *} \\
(1.415)\end{array}$ & $\begin{array}{l}4.026^{* *} \\
(1.416)\end{array}$ & $\begin{array}{l}5.641^{*} \\
(2.204)\end{array}$ & $\begin{array}{l}5.681^{* *} \\
(2.204)\end{array}$ \\
\hline Number of prev. challenges & $\begin{array}{l}-0.004 \\
(0.002)\end{array}$ & $\begin{array}{l}-0.004 \\
(0.002)\end{array}$ & $\begin{array}{l}-0.001 \\
(0.003)\end{array}$ & $\begin{array}{l}-0.001 \\
(0.003)\end{array}$ \\
\hline Constant & $\begin{array}{c}1.292^{* * *} \\
(0.172)\end{array}$ & $\begin{array}{c}1.453^{* * *} \\
(0.181)\end{array}$ & $\begin{array}{c}-1.776^{\text {*** }} \\
(0.232)\end{array}$ & $\begin{array}{c}-1.573^{* * *} \\
(0.258)\end{array}$ \\
\hline Observations & \multicolumn{2}{|c|}{1239} & \multicolumn{2}{|c|}{1229} \\
\hline Individuals & \multicolumn{2}{|c|}{319} & \multicolumn{2}{|c|}{317} \\
\hline Challenges & \multicolumn{2}{|c|}{42} & \multicolumn{2}{|c|}{42} \\
\hline Strata & \multicolumn{2}{|c|}{12} & \multicolumn{2}{|c|}{12} \\
\hline Individual-level variance & 0.300 & 0.301 & 0.344 & 0.346 \\
\hline Challenge-level variance & 0.021 & 0.018 & 0.060 & 0.059 \\
\hline Stratum-level variance & 0.116 & 0.110 & 0.092 & 0.083 \\
\hline Log Likelihood & -3847 & -3843 & 614 & 616 \\
\hline $\mathrm{AIC}$ & 7712 & 7708 & -1209 & -1210 \\
\hline$\Delta \chi^{2}$ & \multicolumn{2}{|c|}{$7^{2.537} 7^{*}(2 \mathrm{df})$} & \multicolumn{2}{|c|}{$4.682(2 \mathrm{df})$} \\
\hline
\end{tabular}

Note: Coefficients and standard errors (in brackets) for: (1) mixed effects gamma regression for the the number of submissions the coder made in the challenge; (2) mixed effects beta regression for the duration of the coder's participation in the challenge, measured as the difference between the time of their last and first submissions, divided by the duration of the challenge. The models include weights by stratum and control for treatment ordering effects using the number of previous challenges the coder has participated in. The models also include random intercepts by individual, challenge, and stratum.

${ }^{*} \mathrm{p}<0.05 ;{ }^{* *} \mathrm{p}<0.01 ;{ }^{* * *} \mathrm{p}<0.001$ 
Table S7: Results at the individual level for the timing, length, and complexity of the first submission.

\begin{tabular}{|c|c|c|c|c|c|c|}
\hline & \multicolumn{2}{|c|}{ Timing } & \multicolumn{2}{|c|}{ Length } & \multicolumn{2}{|c|}{ Code complexity } \\
\hline & $(1.1)$ & $(1.2)$ & $(2.1)$ & $(2.2)$ & $(3.1)$ & $(3.2)$ \\
\hline Relative scoring & & $\begin{array}{c}0.319 \\
(0.174)\end{array}$ & & $\begin{array}{c}-0.353^{*} \\
(0.175)\end{array}$ & & $\begin{array}{c}-0.441^{*} \\
(0.217)\end{array}$ \\
\hline Relative scoring $\times$ Rating & & $\begin{array}{l}-0.400 \\
(0.218)\end{array}$ & & $\begin{array}{l}1.442^{*} \\
(0.577)\end{array}$ & & $\begin{array}{l}1.274^{*} \\
(0.615)\end{array}$ \\
\hline Relative scoring $\times$ Rating $^{2}$ & & & & $\begin{array}{c}-1.218^{*} \\
(0.530)\end{array}$ & & $\begin{array}{l}-0.998 \\
(0.562)\end{array}$ \\
\hline Rating & $\begin{array}{c}0.183 \\
(0.596)\end{array}$ & $\begin{array}{c}0.411 \\
(0.613)\end{array}$ & $\begin{array}{l}2.685^{* *} \\
(0.967)\end{array}$ & $\begin{array}{c}1.848 \\
(1.027)\end{array}$ & $\begin{array}{l}3.043^{* *} \\
(0.997)\end{array}$ & $\begin{array}{l}2.361^{*} \\
(1.062)\end{array}$ \\
\hline Rating $^{2}$ & $\begin{array}{l}-0.368 \\
(0.548)\end{array}$ & $\begin{array}{l}-0.368 \\
(0.550)\end{array}$ & $\begin{array}{c}-4.659^{*} \\
(2.127)\end{array}$ & $\begin{array}{l}-3.891 \\
(2.156)\end{array}$ & $\begin{array}{l}-5.510^{*} \\
(2.189)\end{array}$ & $\begin{array}{l}-5.003^{*} \\
(2.222)\end{array}$ \\
\hline Rating $^{3}$ & & & $\begin{array}{l}3.027^{*} \\
(1.359)\end{array}$ & $\begin{array}{l}2.977^{*} \\
(1.357)\end{array}$ & $\begin{array}{l}3.608^{* *} \\
(1.396)\end{array}$ & $\begin{array}{l}3.639^{* *} \\
(1.395)\end{array}$ \\
\hline Number of prev. challenges & $\begin{array}{l}-0.004 \\
(0.003)\end{array}$ & $\begin{array}{l}-0.004 \\
(0.003)\end{array}$ & $\begin{array}{l}-0.002 \\
(0.002)\end{array}$ & $\begin{array}{l}-0.002 \\
(0.002)\end{array}$ & $\begin{array}{l}-0.002 \\
(0.002)\end{array}$ & $\begin{array}{l}-0.002 \\
(0.002)\end{array}$ \\
\hline Constant & $\begin{array}{c}-0.706^{* * *} \\
0.180\end{array}$ & $\begin{array}{c}-0.893^{* * *} \\
(0.206)\end{array}$ & $\begin{array}{c}4.759^{* * *} \\
(0.166)\end{array}$ & $\begin{array}{c}4.956^{* * *} \\
(0.194)\end{array}$ & $\begin{array}{c}3.396^{* * *} \\
(0.182)\end{array}$ & $\begin{array}{c}3.639^{* * *} \\
(0.222)\end{array}$ \\
\hline Observations & \multicolumn{2}{|c|}{1229} & \multicolumn{2}{|c|}{1029} & \multicolumn{2}{|c|}{1188} \\
\hline Individuals & \multicolumn{2}{|c|}{317} & \multicolumn{2}{|c|}{280} & \multicolumn{2}{|c|}{308} \\
\hline Challenges & \multicolumn{2}{|c|}{42} & \multicolumn{2}{|c|}{40} & \multicolumn{2}{|c|}{42} \\
\hline Strata & \multicolumn{2}{|c|}{12} & \multicolumn{2}{|c|}{11} & \multicolumn{2}{|c|}{12} \\
\hline Individual-level variance & 0.374 & 0.374 & 0.196 & 0.194 & 0.192 & 0.190 \\
\hline Challenge-level variance & 0.053 & 0.053 & 0.076 & 0.078 & 0.187 & 0.187 \\
\hline Stratum-level variance & 0.064 & 0.064 & 0.087 & 0.084 & 0.110 & 0.111 \\
\hline Log Likelihood & 534 & 534 & -6395 & -6391 & -5848 & -5845 \\
\hline $\mathrm{AIC}$ & -1048 & -1048 & 12807 & 12807 & 11714 & 11714 \\
\hline$\Delta \chi^{2}$ & \multicolumn{2}{|c|}{$3.869(2 \mathrm{df})$} & \multicolumn{2}{|c|}{$6.630(3 \mathrm{df})$} & \multicolumn{2}{|c|}{$6.847(3 \mathrm{df})$} \\
\hline
\end{tabular}

Note: Coefficients and standard errors (in brackets) for: (1) mixed effects beta regression for the timing of the first submission, measured as proportion of the challenge duration; (2) mixed effects gamma regression for the number of lines of the first submission; (3) mixed effects gamma regression for the cyclomatic complexity of the code in the first submission. The models include weights by stratum and control for treatment ordering effects using the number of previous challenges the coder has participated in. The models also include random intercepts by individual, challenge, and stratum.

${ }^{*} \mathrm{p}<0.05 ;{ }^{* *} \mathrm{p}<0.01 ;{ }^{* * *} \mathrm{p}<0.001$ 
Table S8: Results for performance, likelihood to return, and effort for first-time contestants.

\begin{tabular}{|c|c|c|c|c|c|}
\hline & $\begin{array}{c}\text { Code complexity } \\
(1)\end{array}$ & $\begin{array}{c}\text { If returns } \\
(2)\end{array}$ & $\begin{array}{c}\text { Total code lines } \\
\text { (3) }\end{array}$ & $\begin{array}{c}\text { Num. submissions } \\
(4)\end{array}$ & $\begin{array}{c}\text { Time in challenge } \\
(5)\end{array}$ \\
\hline Relative scoring & $\begin{array}{c}0.052 \\
(0.148)\end{array}$ & $\begin{array}{l}-0.256 \\
(0.216)\end{array}$ & $\begin{array}{c}0.050 \\
(0.158)\end{array}$ & $\begin{array}{l}-0.147 \\
(0.129)\end{array}$ & $\begin{array}{c}-0.231^{*} \\
(0.114)\end{array}$ \\
\hline Constant & $\begin{array}{c}4.416^{* * *} \\
(0.144)\end{array}$ & $\begin{array}{c}0.221 \\
(0.223)\end{array}$ & $\begin{array}{l}6.204^{* * *} \\
(0.141)\end{array}$ & $\begin{array}{c}1.898^{* * *} \\
(0.105)\end{array}$ & $\begin{array}{c}-0.985^{* * *} \\
(0.107)\end{array}$ \\
\hline Individuals & 1159 & 1198 & 1055 & 1198 & 1198 \\
\hline Challenges & 41 & 41 & 41 & 41 & 41 \\
\hline Strata & 13 & 13 & 13 & 13 & 13 \\
\hline Challenge-level variance & 0.142 & 0.200 & 0.146 & 0.093 & 0.046 \\
\hline Stratum-level variance & 0.102 & 0.268 & 0.066 & 0.017 & 0.037 \\
\hline Log Likelihood & -6178 & -726 & -7658 & -3436 & 1682 \\
\hline $\mathrm{AIC}$ & 12366 & 1461 & 15326 & 6882 & -3355 \\
\hline
\end{tabular}

Note: Coefficients and standard errors (in brackets) for: (1) mixed effects gamma regression for the cyclomatic complexity of the code in the final submission; (2) mixed effects logistic regression for the likelihood to participate in at least one other challenge on Topcoder; (3) mixed effects gamma regression for the the total number of code lines the coder wrote in the challenge; (4) mixed effects gamma regression for the the number of submissions the coder made in the challenge; (5) mixed effects beta regression for the duration of the coder's participation in the challenge, measured as the difference between the time of their last and first submissions, divided by the duration of the challenge. The models include weights by stratum and random intercepts by challenge and stratum.

${ }^{*} \mathrm{p}<0.05 ;{ }^{* *} \mathrm{p}<0.01 ;{ }^{* * *} \mathrm{p}<0.001$ 